\title{
Novel orodispersible compositions of nutraceuticals prepared by the technology of extrusion-spheronization
}

\author{
Namita Desai ${ }^{1}$, Satish Jain ${ }^{2}$, P. S. Pirthipal Singh ${ }^{2}$, Purnima Amin ${ }^{2 *}$ \\ ${ }^{1}$ Bombay College of Pharmacy, Kalina, Santacruz (E), Mumbai 400098, India. \\ ${ }^{2}$ Pharmaceutical Sciences and Technology Division, Institute of Chemical Technology (Autonomous), Matunga, Mumbai 400019, India.
}

\begin{tabular}{|c|c|}
\hline ARTICLE INFO & ABSTRACT \\
\hline $\begin{array}{l}\text { Article history: } \\
\text { Received on: } 18 / 12 / 2016 \\
\text { Accepted on: } 12 / 02 / 2017 \\
\text { Available online: } 30 / 04 / 2017\end{array}$ & $\begin{array}{l}\text { European Medicines Agency (EMA) characterized liquid formulations as most appropriate for pediatric } \\
\text { population but this includes drawbacks of lesser stability, more shelf space and dosing error in comparison to } \\
\text { solid oral dosage forms. Orodispersible systems hold great promise for children as they are easy to } \\
\text { administer, do not require additional water, are difficult to spit out, stable, thus combining advantages of solid }\end{array}$ \\
\hline $\begin{array}{l}\text { Key words: } \\
\text { Orodispersible pellets, } \\
\text { Calcium and Cholecalciferol, } \\
\text { Extrusion - Spheronization, } \\
\text { pediatric. }\end{array}$ & $\begin{array}{l}\text { Calcium and Cholecalciferol, as nutraceuticals using the technology of Extrusion - Spheronization. Calcium } \\
\text { deficiency is manifested in the bones and teeth of all young animal species, including humans. Effects include } \\
\text { stunted growth, poor quality bones and teeth, bone malformation. The experimental work included } \\
\text { optimization of the extrusion - spheronization processing parameters and choice of excipients, which critically } \\
\text { affected the product quality to produce orodispersible pellets. The developed orodispersible pellets had } \\
\text { satisfactory quality control parameters and formed soft palatable mass on contact with salivary fluid which } \\
\text { could be easily swallowed. The in vitro dissolution studies indicated rapid release of active and the pellets } \\
\text { were found to be stable. An additional advantage of these orodispersible pellets is sprinkling over soft food, } \\
\text { juices etc for food fortification prior to administration. }\end{array}$ \\
\hline
\end{tabular}

\section{INTRODUCTION}

In 2008, a WHO expert forum reviewed the existing pediatric formulations and attempted to identify future research needs to improve the development of preferred dosage forms for children. Previous references of EMA such as 'Reflection paper: formulations of choice for the pediatric population' characterized liquid formulations as most appropriate for young pediatric population (birth to eight years). Large volume doses may be inconvenient for both patient and care - giver. The reflection paper also encouraged oral multiparticulates in administering drugs to pediatrics aged 2-16 years (EMA, 2006; Batchelor et al., 2015). These can be dosed directly into the

\footnotetext{
* Corresponding Author

E-mail: purnima.amin @yahoo.co.in
}

mouth of the pediatric patient or by mixing the prescribed dose with a small amount of soft food or with a drink prior to administration. Formulations can be provided in a bottle with dosing scoop or single-dose sachets. They may also be supplied in the form of capsules, the contents of which can be sprinkled onto food. The reflection paper also discussed that orodispersible dosage forms hold great promise for children as they are easy to administer, do not require additional water and as long as dispersion is rapid, are difficult to spit out and could provide a range of dosages appropriate for use in younger children (EMA, 2006; Kristensen, 2012). The need for a multidisciplinary approach to pediatric medicines was highlighted and the potential of a 'platform' solid dosage form (e.g. granules or pellets) as a preliminary form providing flexibility for further processing into a range of alternative pediatric drug delivery system was presented (WHO, 2008). 
Hence, the purpose of this study was to combine multiparticulates and orodispersible dosage forms to prepare orodispersible pellets as an innovative dosage form for pediatric population. These pellets formed soft palatable mass on contact with salivary fluid and could then be easily swallowed. Pellets were the choice of formulation because they offer the advantages of better appearance and are uniformly sized, especially as compared to granules, divided into different dose strengths, improved flow properties and flexibility in formulation development, manufacture and dosage, better availability, can be sprinkled over soft food before administering to pediatrics and also provide a platform technology. Thus, these orodispersible pellets combine the advantages of both solid and liquid dosage forms and also provide technological advantages over granules, powders etc. The EMA reflection paper also proposed to consider the modification of standard technologies in the development of preferred pediatric dosage forms (EMA, 2006; Ernest et al., 2012; Slavkova and Breitkreutz, 2015). Thus, these orodispersible pellets were prepared using the technique of Extrusion Spheronization that offers pellets with high drug loading, avoiding the coating step and is relatively economical as compared to other pelletization techniques (Ghebre-Sellassie, 1989; Erkoboni, 2003; Poddar et al., 2016; Tatavarti and Kesisoglou, 2015; Vervaet et al., 1995). Extrusion - Spheronization is exploited in the present work for developing novel orodispersible pellets of a calcium supplement against deficiency, a global health concern and especially because calcium for supplementation is required in high doses. A positive calcium balance is required throughout growth, particularly during the first 2 years of life, during puberty and adolescence. These age groups, therefore constitute populations at risk for calcium deficiency, as do pregnant women (especially in the last trimester), lactating women, postmenopausal women, and possibly, elderly men. If adequate calcium intakes are not met from the diet, additional intake can be achieved by supplementation of diet (Halsted, 2000; Wildman, 2001). The present research focuses on development of palatable calcium supplement formulated as orodispersible pellets to improve compliance and possibly address the issue of mineral deficiency in pediatric population along with choice of food fortification. Cholecalciferol increases the calcium absorption and is given in combination with calcium supplements (DeLuca, 2004). Extrusion - spheronization can also be extended to other nutraceuticals and drugs as a platform technology, especially for high dose actives.

\section{MATERIALS AND METHODS}

\section{Materials}

Calcium citrate, (99.76\% purity) and Cholecalciferol (99.67\% purity) was received as a gift sample from Bajaj Healthcare Ltd, Mumbai, India. Avicel ${ }^{\circledR}$ PH101 was purchased from Signet Chemical Corporation, Mumbai, India. The Instacoat ${ }^{\circledR}$ flavours were purchased from Ideal Cures Pvt Ltd, Mumbai, India. Indion ${ }^{\circledR} 414$ was purchased from Ion Exchange (I) Ltd. All the other excipients used were GRAS listed.

\section{Selection of appropriate calcium source}

An estimated $85 \%$ of all calcium supplements contain calcium carbonate. The main reason for the wide use of calcium carbonate is its being least expensive and contains about $40 \%$ elemental calcium. However, the disadvantages of Calcium carbonate are only $22 \%$ of the calcium is absorbed from the carbonate, in fasted state, insolubility in neutral or alkaline $\mathrm{pH}$, constipation, bloating and chalky mouthfeel. Calcium carbonate is not absorbed well especially in people with low gastric acid levels, such as the elderly. But, Calcium citrate has been shown to be better absorbed than calcium carbonate by approximately $22-27$ $\%$ either with meals or on an empty stomach. Calcium citrate is $21 \%$ elemental calcium but $50 \%$ of the calcium is absorbed from the citrate.

Also, Calcium citrate does not need as low a $\mathrm{pH}$ to dissolve as calcium carbonate. These forms of calcium thus can also be suitable for persons with hypochlorhydria or achlorhydria (Sakhaee et al., 1999; Heller et al., 1999). Calcium citrate was available in different forms as powder, granular and micronized. Micronized and powder form of calcium citrate were selected over the granular form for further study, since Calcium citrate was to be further processed into pellets. A study of rate of dissolution of both the forms of Calcium citrate using U.S.P. Type II Electrolab Dissolution Testing Equipment with $0.1 \mathrm{~N}$ Hydrochloric acid as the dissolution medium was performed. Excess of each form of Calcium citrate (micronised and powder) was placed into dissolution vessels $(\mathrm{n}=6)$ containing $900 \mathrm{ml}$ of the media and the apparatus was operated at $75 \mathrm{rpm}$ and bath temperature was set at $37.0 \pm 0.2^{\circ} \mathrm{C}$, respectively. Aliquots were withdrawn at the end of $5,10,15,20$ and 30 minutes and analyzed complexometrically using 0.05M Disodium EDTA as the titrant and hydroxynaphthol blue as indicator, to determine the amount of Calcium citrate dissolved at the end of 30 minutes. Also, the particle size analysis of the micronised and powder samples of Calcium citrate was carried out.

The mean particle diameter of the samples was determined on a Particle Size Analyzer CILAS 1064 (M/s Advance Scientific Equipment) and the data integration was done using Size Expert V7.00. Further, comparative evaluation of Calcium citrate (micronized) and Calcium carbonate as sources of calcium, for solubility characteristics was carried out (Heaney et al., 2001) Briefly, excess of each of the above mentioned calcium salts were placed in $20 \mathrm{ml}$ of USP buffers $\mathrm{pH} 1.2, \mathrm{pH} 4.5, \mathrm{pH} 6.8$, $\mathrm{pH} 7.4$ and $\mathrm{pH} 8.0$ and purified water and the suspensions were placed in mechanical shaker for 48 hours at $37{ }^{\circ} \mathrm{C} \pm 0.5^{\circ} \mathrm{C}$. The suspensions were cyclomixed intermittently. At the end of 48 hours, the suspensions were filtered and analysed by complexometry using $0.05 \mathrm{M}$ EDTA as the titrant and hydroxynaphthol blue as indicator.

\section{Selection of excipients for development of Orodispersible pellets}

Various excipients for development of orodispersible pellets such as Starch 1500, Avicel $^{\circledR}$ PH 101, Mannitol 25, Indion ${ }^{\circledR}$ 
414, Avicel $^{\circledR}$ RC 591, Avicel ${ }^{\circledR}$ CL 611, lactose and sucrose, powdered were studied individually and in combination for their processibility by extrusion - spheronization.

\section{Optimization of extrusion - spheronization}

The process of Extrusion - Spheronization was optimized for dry mixing, wet massing, extrusion, spheronization and drying operations. The mixing operation was performed on a planetary mixer (Hobart Mixer Granulator) for optimum time. The dry blend was then granulated using water $(0.6 \mathrm{ml} / \mathrm{g}-0.8 \mathrm{ml} / \mathrm{g})$. The extrusion process was carried out using both, a single screw extruder axial (manual) developed in our research laboratory, with $L / R$ ratio of 1.7 where $L$ is thickness of screen and $R$ is radius of screen aperture and a die roller extruder (R. R. Enterprises, India). The die roller extruder was operated at speeds of $50 \mathrm{rpm}, 65 \mathrm{rpm}$ and $75 \mathrm{rpm}$.

The optimum extrudates were placed onto the crosshatch spinning plate of the spheronizer and spheronized at speeds of 200 - $800 \mathrm{rpm}$ for a period on $1-8$ minutes. The pellets were then dried in Fluid Bed Dryer or Tray Dryer at $40^{\circ} \mathrm{C}$ for optimum time. The mentioned parameters for Extrusion - Spheronization were optimized to produce fast dispersing pellets.

\section{Development of orodispersible pellets of Calcium and Cholecalciferol}

The formulation development involved selection of excipients that would offer spherical and palatable pellets with rapid dispersion. One dose of pellets in sachets contained Calcium citrate equivalent to $250 \mathrm{mg}$ elemental calcium and Cholecalciferol 200 I.U. Avicel ${ }^{\circledR}$ PH 101 and Avicel ${ }^{\circledR}$ RC 591, in combination were studied as spheronizing aids. Sodium lauryl sulphate and Polysorbate 80 were added as channelizing agents to promote the rapid uptake of salivary fluid and sodium saccharin was the sweetener.

Instacoat ${ }^{\circledR}$ was added as flavour with Mannitol 25 as the diluents providing cooling sensation. Indion ${ }^{\circledR} 414$, Kollidon ${ }^{\circledR}$ CL, Ac-Di-Sol $^{\circledR}$ and starch sodium glycolate were studied as superdisintegrants. The process involved dry blending the nutraceuticals with the optimized excipients and granulating using purified water to form wet mass which was then extruded using a Single Screw Extruder. The extrudates were spheronised on a Spheroniser $S$ - 150, dried in a Fluid Bed Dryer and fractionated.

\section{Characterization of orodispersible pellets:}

The orodispersible pellets that were formed by Extrusion - Spheronization were evaluated for appearance, particle size and other quality control parameters (Bajaj and Sawarkar, 1999; Fonner et al., 1966, Poddar; 2016).

\section{Disintegration}

The orodispersible pellets were placed in $6 \mathrm{ml}$ of simulated salivary fluid and the time required for the pellets to turn soft and leave no palpable core was recorded.
Density

The pellets were weighed accurately ('W' g), introduced into a graduated glass cylinder and unsettled apparent volume in $\mathrm{ml}$ was read as $\mathrm{V}_{\mathrm{o}}$. Then, bulk density was calculated as $\mathrm{W} / \mathrm{V}_{\mathrm{o}}$. The cylinder was then placed on Veego Bulk Density Testing Apparatus (USP 1) and tapped 500 times. The tapped volume was read in $\mathrm{ml}$ as $\mathrm{V}_{\mathrm{a}}$ and tap density was calculated as $\mathrm{W} / \mathrm{V}_{\mathrm{a}}$

\section{Carr's Index}

Carr's Index or $\%$ Compressibility was calculated

$$
\text { as: } \frac{(\text { Tap density-Bulk density }) X 100}{\text { Tap density }}
$$

Carr's Index is indicative of the flow properties of the material. An index of 5-15 indicates excellent flow properties while $12-21$ is indicative of the need of a glidant to improve the flow. An index of $23-40$ indicates a poor flow of the material.

\section{Hausner's ratio}

Hausner's ratio was calculated as $\frac{\text { Tap density }}{\text { Bulk density }}$

Hausner's ratio is indicative of the flow properties of the material. A value of between $1.25-1.5$ is indicative of the need of a glidant to improve the flow. Values greater than 1.25 indicates poor flow while values less than 1.25 indicates good flow.

\section{Angle of repose}

A glass funnel was clamped to a stand and about $20 \mathrm{~g}$ of the pellets were placed in the funnel and were allowed to flow through the stem of the funnel. The pellets were collected as a heap below the funnel with the tip of the stem of funnel just touching the tip of the heap of pellets. The diameter of the heap formed was measured and the radius was calculated (r). The height of the heap was calculated as h. Angle of repose $=\tan ^{-1}\left(\frac{h}{r}\right)$

\section{Moisture content}

About $25 \mathrm{~g}$ of the sample was placed in the pan of Sakova Infrared Moisture Balance and the moisture content of the pellets was determined.

\section{Porosity}

True density was determined using a pycnometer. Benzene with a specific gravity of $0.878 \mathrm{~g} / \mathrm{ml}$ was employed as the liquid for displacement. The specific gravity bottle was filled with benzene, the volume of benzene displaced by $1 \mathrm{~g}$ of the pellets was noted and the true density was determined as follows:

True density $=\frac{\text { Weight of pellets }}{\text { Volume of benzene displaced }}$

Porosity $(\varepsilon)=1-\frac{\text { Bulk density }}{\text { Tap density }}$

\section{Pellet hardness}

Hardness determination of the pellets involved shaking the pellets in a closed container for a constant period of time and then measuring the percentage by weight of the material retained on a $40-$ mesh sieve. This study was hence carried out in a 
Magumps Friabilator run at $25 \mathrm{rpm}$ for 4 minutes and $10 \mathrm{~g}$ of pellets were employed. The hardness index, $\mathrm{h}$ was calculated as the weight fraction of the material retained as $40-$ mesh oversize following shaking.

\section{Sphericity}

The length and the width of 50 pellets was measured microscopically. The length (l) was measured as the longest axis of the particle and the width (w) was measured across the particle on a line perpendicular to the midpoint of the longest axis. A ratio 1/w was calculated. The sample of 50 pellets was then divided into classes giving a frequency histogram and the relative frequency for each class was calculated.

Sphericity $(\mathrm{S})=1 /\left(\sum\left(b^{2} X r f\right)\right.$ where $\mathrm{b}=$ midpoint of the class, $\mathrm{rf}=$ relative frequency

\section{Assay of Calcium citrate}

The orodispersible pellets were powdered and powder equivalent to $250 \mathrm{mg}$ of elemental calcium was extracted in 250 $\mathrm{ml} 0.1 \mathrm{~N}$ Hydrochloric acid for 4 hours. The suspension was filtered, diluted with water to about $100 \mathrm{ml} .15 \mathrm{ml}$ of $1 \mathrm{~N}$ sodium hydroxide and $300 \mathrm{mg}$ of hydroxy naphthol blue indicator were added and titrated against 0.05M Edetate Disodium VS to blue end point.

\section{Content of Cholecalciferol}

The content of Cholecalciferol including the overages was determined by High Performance Liquid Chromatography. Pellets containing about 200 I.U of Cholecalciferol were crushed to a fine powder and were quantitatively transferred to amber volumetric flasks (capacity $25 \mathrm{ml}$ ), in triplicates and stirred with mobile phase for 2 hours. The solutions were centrifuged for 5 minutes at $3000 \mathrm{rpm}$ using Superfit centrifuge and injected into the chromatographic system. Chromatography was performed on Waters Spherisorb $^{\circledR}$ RP - $18(5 \mu \mathrm{m})$ ODS2 (4.6 x $\left.250 \mathrm{~mm}\right)$ Analytical column. The mobile phase was prepared by mixing Acetonitrile, Methanol and water in a ratio of 50:50:2 (v/v/v) respectively.

The mobile phase was filtered through a nylon membrane (0.45 $\mu \mathrm{m})$ and degassed by sonication prior to use. Chromatography was performed at room temperature under isocratic conditions at a flow rate of $1.2 \mathrm{ml} /$ minute. Detection was done at $254 \mathrm{~nm}$ and the detector sensitivity was set at 0.16 AUFS.

\section{In - vitro dissolution study}

Dissolution testing was performed on using U.S.P. Type II Electrolab Dissolution Testing Equipment using $0.1 \mathrm{~N}$ Hydrochloric acid as the dissolution medium. $2 \mathrm{~g}$ pellets were placed into each dissolution vessel $(n=6)$ containing $900 \mathrm{ml}$ of the dissolution media and the apparatus was operated at $75 \mathrm{rpm}$ and bath temperature was set at $37.0 \pm 0.2^{\circ} \mathrm{C}$, respectively. $25 \mathrm{ml}$ aliquots were withdrawn at the end of $5,10,15,20$ and 30 minutes. $20 \mathrm{ml}$ solution from the withdrawn aliquots was then analyzed complexometrically using 0.05M Disodium EDTA as the titrant, to determine the amount of calcium citrate dissolved at each time point.

\section{Microbial Limits Tests}

The total bacterial count does not exceed 3000 per $g$ and the total combined molds and yeast count does not exceed 300 per g. Pellets should also meet the requirements of the tests for absence of Salmonella species and Escherichia coli and for the absence of Staphylococcus aureus. The microbial limit tests were performed as per I.P.

\section{Stability studies}

The optimized formulation was packed in sachets of aluminum foil lined with polyethylene of thickness $(96.33 \pm 1.86$ microns) and subjected to accelerated stability testing as per ICH guidelines. The samples were placed in Thermolab Humidity cum Photostability Chambers at conditions of $25^{\circ} \mathrm{C} /$ $60 \%$ Relative Humidity, $30^{\circ} \mathrm{C} / 65 \%$ Relative Humidity and $40^{\circ} \mathrm{C} /$ $75 \%$ Relative Humidity and the samples were analyzed for 6 months.

\section{Statistical analysis}

The results were expressed as the mean standard deviation and statistical analysis was carried out using appropriate method wherever necessary.

\section{RESULTS AND DISCUSSION}

\section{Selection of appropriate calcium source}

The micronised form of Calcium citrate had faster rate of dissolution due to finer particle size and this form was selected over the powder form for the formulation of Calcium and Cholecalciferol orodispersible pellets (Table 1). Also, the solubility of Calcium citrate, micronised was greater at various pHs as compared to the solubility of Calcium carbonate. Because of the better solubility profile of micronised form of Calcium citrate over a wide range of $\mathrm{pH}$, the developed pellets can hence be used in fortification of fruit juices, beverages, soft food etc. (Nicar and Pak, 1985). Hence, due to improved solubility profile as indicated in (Fig 1) Calcium citrate, micronised was chosen over Calcium carbonate as calcium source for development of orodispersible pellets

Table 1: Selection of appropriate Calcium source.

\begin{tabular}{ccc}
\hline $\begin{array}{c}\text { Form of Calcium } \\
\text { citrate }\end{array}$ & $\begin{array}{c}\text { Mean Particle } \\
\text { Diameter }\end{array}$ & In - vitro Dissolution \\
\hline $\begin{array}{c}\text { Calcium citrate, } \\
\text { micronised }\end{array}$ & 12 microns & $\begin{array}{c}4.12 \mathrm{mg} / \mathrm{ml} \text { of Calcium } \\
\text { citrate dissolved at the end } \\
\text { of } 30 \mathrm{minutes}\end{array}$ \\
\hline $\begin{array}{c}\text { Calcium citrate, } \\
\text { powder }\end{array}$ & 39 microns & $\begin{array}{c}2.16 \mathrm{mg} / \mathrm{ml} \text { of Calcium } \\
\text { citrate dissolved at the end } \\
\text { of } 30 \text { minutes }\end{array}$ \\
\hline
\end{tabular}




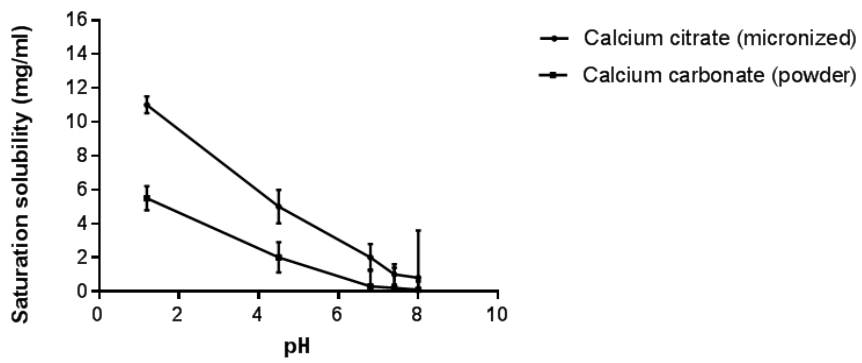

Fig. 1: Selection of Calcium source on the basis of solubility.

\section{Selection of excipients for development of orodispersible pellets}

From the various excipients that were studied, Starch 1500 on aqueous granulation formed sticky mass that could not be extruded. All the grades of Avicel ${ }^{\circledR}$ such as PH, RC grades etc could be extruded and spheronized. Lactose could be extruded but not spheronized and remained as long rods on spheronization. Mannitol 25 alone could be granulated but could not be extruded as it crumbled to powder. Indion ${ }^{\circledR} 414$ could be granulated with purified water but could not be extruded. Sucrose, powdered could be granulated with water to form a wet mass, however on extrusion, sucrose sticks to the extruder rollers and the scrapper blade and could not be extruded. The microscopic structure of microcrystalline cellulose as Avicel $^{\circledR}$ is seen as a random aggregation of filamentous microcrystals which create a high internal porosity and a large surface area, approximately $130-270$ $\mathrm{m}^{2} / \mathrm{g}$. This provides a highly absorbent and moisture retaining characteristics that makes microcrystalline cellulose a unique material for extrusion (Swarbrick and Boylan, 1998). Also, the added liquid during granulation serves as a lubricant at the die end plate during the extrusion process. During the spheronization process, the long extrudates are broken up into shorter lengths. As the extrudates are spun on the spheronization plate, the moisture is forced from the interior to the exterior surface and this available moisture plasticizes the surfaces and aids in the formation of spheres (Wan et al., 1993). A part of Avicel ${ }^{\circledR}$ was replaced with Mannitol 25 or lactose, respectively and evaluated for processibility for reducing the excipient cost. It was found that Mannitol 25 could be added in almost $90 \%$ proportion to Avicel ${ }^{\circledR}$ PH 101 and almost $60 \%$ proportion to Avicel ${ }^{\circledR}$ RC 591 and yet retain the sphericity of the pellets. Lactose could be present in almost $50 \%$ of Avicel ${ }^{\circledR}$ without affecting the sphericity of pellets.

\section{Optimization of extrusion - spheronization}

The quality of pellets is greatly influenced by the extrusion spheronization processing parameters (Podczeck and Newton, 2014). The quantity of water required for granulation affects both extrusion as well as spheronization. The level of water for granulation was optimised at $0.6 \mathrm{ml} / \mathrm{g}-0.8 \mathrm{ml} / \mathrm{g}$ of the dry blend for roping action during spheronization. Higher water levels caused balling and lower water levels gave friable extrudates that could not be spheronized. The quantity of water required for extruding the mass in a die roller extruder is less than that required by Single Screw Extruder. This is because in a die roller extruder, there is consolidation of the material processed, since the material is first compacted by the rollers and then extruded (Fig. 2). Hence, the extrudates have sufficient mechanical strength to withstand subsequent spheronization. While in case of Single Screw Extruder, there is a considerably lesser degree of compaction during extrusion and the additional amount of water acts as a binder to impart strength to the pellets to withstand spheronization. This is also indicated by the true density of the extrudates which was $2.571 \mathrm{~g} / \mathrm{cc}$ when produced by single screw extruder as compared to $2.857 \mathrm{~g} / \mathrm{cc}$ when produced by die roller extruder. The lesser extent of compaction in Single Screw Extruder (Fig. 3) was favorable for development of orodispersible pellets with rapid disintegration properties and hence was selected as extruder for pellet development.

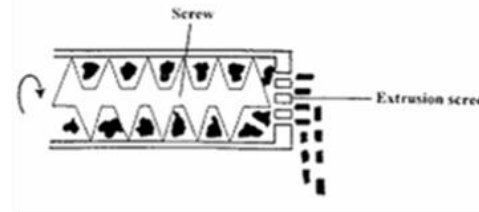

Screw extruder axial

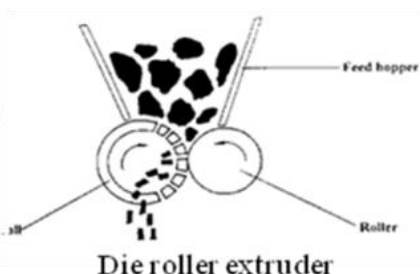

Die roller extruder
Fig. 2: Different types of extruder used in the extrusion process (Vervaet et al., 1995).

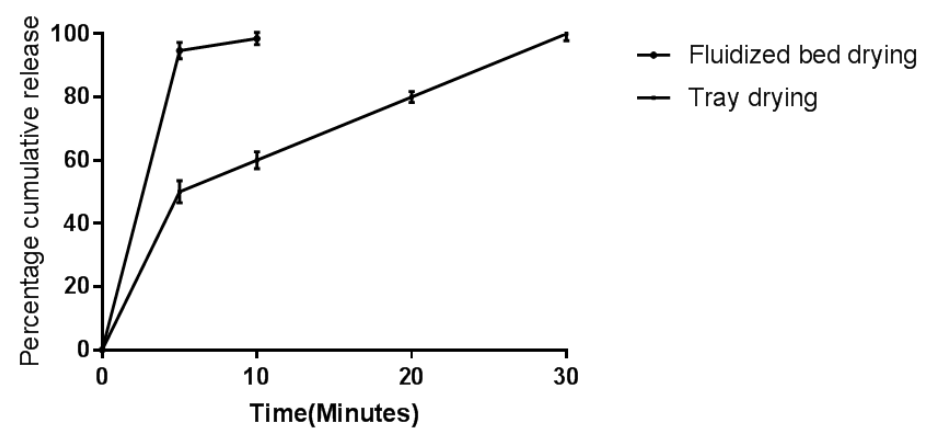

Fig. 3: Effect of drying technique at $40^{\circ} \mathrm{C}$ on drug release from Calcium and Cholecalciferol orodispersible pellets.

The screw extruder was more suitable to continuous extrusion since the perforations in the die roller were blocked on prolonged operation for batch sizes greater than $200 \mathrm{~g}$, thus affecting the product yield. The extruder screen sizes of $0.5 \mathrm{~mm}$, $0.6 \mathrm{~mm}, 0.8 \mathrm{~mm}, 1 \mathrm{~mm}$ were suitable for preparing the pellets and $0.5 \mathrm{~mm}$ extruder screen was chosen to produce finer pellets for rapid disintegration due to increased surface area. Spheronization speeds of less than $500 \mathrm{rpm}$ and dwell time less than 4 minutes formed a mixture of dumbbell shaped and ellipsoid pellets while speeds more than $600 \mathrm{rpm}$ and dwell time more than 5 minutes generated more fines. The optimum spheronization speed of 500 $\mathrm{rpm}-600 \mathrm{rpm}$ and dwell time of $4-5$ minutes gave spherical pellets. The pellets dried using a tray dryer had longer processing times $\left(40^{\circ} \mathrm{C}, 4\right.$ hours) and considerable hardness over the pellets dried using a Fluid Bed Dryer $\left(40^{\circ} \mathrm{C}, 30\right.$ minutes $)$. Based on the different rate of moisture removal, means of heat and mass transfer and static or dynamic nature of the bed, the different drying 
techniques produced pellets of different structural and mechanical properties (Bashaiwoldu et al., 2004). The pellets dried in a Fluid Bed Dryer were more porous as indicated by more than $90 \%$ drug release in 10 minutes as against about $60 \%$ drug release in 10 minutes from tray dried pellets (Fig. 3). The pellets dried in a Fluid Bed Dryer had porosity of $78 \%$ while those dried in Tray Dryer had porosity of $70 \%$ indicating the differences in water imbibing capacity which caused pellet disintegration.

\section{Development of orodispersible pellets of Calcium and Cholecalciferol}

Avicel $^{\circledR}$ PH 101 and Avicel $^{\circledR}$ RC 591 were selected in combination to produce optimum balance of sphericity and mouthfeel respectively of the orodispersible pellets Avicel ${ }^{\circledR} \mathrm{PH}$ 101 is microcrystalline cellulose while Avicel $^{\circledR}$ RC 591 is combination of microcrystalline cellulose and sodium carboxymethylcellulose $(8.3-11.8 \%)$. $\left(\right.$ Avicel $^{\circledR}$, FMC; 1995) The concentrations of sodium lauryl sulphate and polysorbate 80 as channelizing agents and sodium saccharin as sweetener were optimized to produce palatable pellets as excess amounts produced bitterness.

Table 2: Optimized formula of Calcium and Cholecalciferol Orodispersible pellets.

\begin{tabular}{cc}
\hline Ingredients & Mg \\
\hline Calcium Citrate USP & 1190 equivalent to 250 mg elemental calcium \\
Cholecalciferol I.P & $200 \mathrm{I} . \mathrm{U}$ \\
Sodium saccharin & 40 \\
Instacoat@® Flavor (Lime) & 50 \\
Indion 414 & 200 \\
Sodium lauryl sulfate & 8 \\
Polysorbate 80 & 8 \\
Methyl Paraben Sodium & 3.6 \\
Propyl Paraben Sodium & 0.4 \\
Avicel@ PH 101 & 200 \\
Avicel@ RC 591 & 240 \\
Mannitol - 25(40\#) & q.s $2000 \mathrm{mg}$ \\
\hline
\end{tabular}

Instacoat ${ }^{\circledR}$ was added as flavour with Mannitol 25 as the diluent to produce cooling sensation in the mouth. Kollidon ${ }^{\circledR} \mathrm{CL}$, Ac-Di-Sol ${ }^{\circledR}$ and starch sodium glycolate as superdisintegrants, individually gave disintegration time of more than 3 minutes. Indion ${ }^{\circledR} 414$ as superdisintegrant gave rapid disintegration within 1 minute and hence was optimized. The optimized formula for orodispersible pellets of Calcium and Cholecalciferol is as shown in Table 2. The process was optimized for dry blending of ingredients for $15 \mathrm{~min}$, granulating using purified water $(0.6-0.7$ $\mathrm{ml} / \mathrm{g}$ of the dry blend) and extrusion using a Single Screw Extruder $(0.5 \mathrm{~mm}$ screen). The extrudates were spheronised on a Spheroniser $\mathrm{S}-150$ at $800 \mathrm{rpm}$ for $4-5$ minutes using a $2 \mathrm{~mm}$ cross hatched plate. The pellets formed were dried in a Fluid Bed Dryer at $40^{\circ} \mathrm{C}$ for 30 minutes and then fractionated using $16 \#$ and 20\# sieves.

\section{Characterization of orodispersible pellets}

The pellets were yellow colored, spherical, uniform in appearance having particle size $400-800$ microns. The pellets showed in vitro disintegration time of 30 seconds and formed a soft mass with no palpable core. The bulk density and tap density were found to be $0.656 \mathrm{~g} / \mathrm{ml}$ and $0.722 \mathrm{~g} / \mathrm{ml}$ respectively. The value of Carr's Index, Hausner's Ratio, angle of repose as $9.14 \%$, 1.10 and $20^{\circ}$ respectively indicated excellent flow properties. The true density of the pellets was $2.8 \mathrm{~g} / \mathrm{ml}$ showing porosity of $78 \%$ indicating optimum water imbibing capacity for rapid disintegration. The pellets showed moisture content of less than $2 \% \mathrm{w} / \mathrm{w}$. The hardness of the pellets was $99.84 \%$ and sphericity was found to be $90.70 \%$. The results of assay indicated $99.56 \pm$ $1.788 \%$ of Calcium citrate and $156.72 \pm 6.48 \%$ Cholecalciferol in the pellets. The microbial studies indicated total bacterial count of less than $10 \mathrm{cfu} / \mathrm{g}$ and absence of Salmonella species, Escherichia coli, Staphylococcus aureus and fungal count. Fig. 4 indicates rapid release of Calcium citrate from the pellets in an in - vitro dissolution study which can be attributed to the rapid disintegration of the pellets due to fine size suitable for dispersion in the mouth.

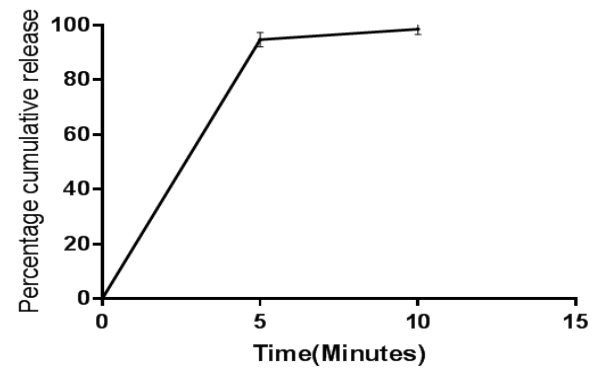

Fig. 4: In vitro drug release from Calcium and Cholecalciferol orodispersible pellets.

\section{CONCLUSIONS}

Palatable orodispersible pellets of Calcium and Cholecalciferol as nutraceuticals were successfully developed using the technology of Extrusion - Spheronization. The process of Extrusion - Spheronization was optimized for processing parameters and the excipients selected for the orodispersible pellets afforded a palatable composition that formed a soft mass when placed in contact with salivary fluid and can be easily swallowed. Calcium deficiency is the most prevalent among children due poor dietary habits. This can lead to weak bones and hence osteoporosis in the later stages of life. Hence, supplementing the diet with Calcium is necessary. Calcium citrate was selected as the source of Calcium over Calcium carbonate due to its improved solubility and bioavailability. Cholecalciferol is given in combination with Calcium since it increases calcium absorption. The developed orodispersible pellets offer an additional benefit over mouth dissolving tablets as these can be sprinkled over fruit juices, soft foods or puddings and administered, if the child refuses to accept medicine. Thus, the process of Extrusion - Spheronization that was so far employed for the development of modified release pellets was successfully 
extrapolated for the development of novel fast dissolving dosage forms viz palatable orodispersible pellets.

\section{ACKNOWLEDGEMENTS}

Authors are grateful to Bajaj Healthcare Ltd, Mumbai, India, Signet Chemical Corporation, Mumbai, India, Ideal Cures Pvt Ltd, Mumbai, India and Ion Exchange (I) Ltd for providing gift samples of drugs and excipients.

Conflict of Interests: There are no conflicts of interest.

\section{REFERENCES}

Avicel $P H^{\circledR}$. Microcrystalline Cellulose, NF, Ph. Eur., JP, BP, Product Literature, FMC Corporation. 1995.

Batchelor H, Salunke S and Tuleu C. Formulating better medicines for children-reflections. Int J Pharm, 2015; 492 (1-2): 301-303

Bajaj AN, Sawarkar SP. Pelletization by Extrusion Spheronization Technique Process Optimization. Indian Drugs, 1999; 36 (1): $44-49$.

Bashaiwoldu AB, Podczeck F. and Newton JM. A study on the effect of drying techniques on the mechanical properties of pellets and compacted pellets. Eur. J. Pharm. Sci, 2004; 21: 119 - 129

DeLuca HF. Overview of general physiologic features and functions of vitamin D. Am J Clin Nutr, 2004; 80 (suppl): 1689S - 96S

Erkoboni DF. 2003. Extrusion Spheronization, in GhebreSellassie. I and Martin C, Pharmaceutical Extrusion Technology, Marcel Dekker Inc, New York. pp. 277

Ernest TB, Craig J, Nunn A, Salunke S, Tuleu C, Breitkreutz J, Alex R, Hempenstall J. Preparation of medicines for children- A hierarchy of classification. Int J Pharm, 2012; 435 (2): 124-130

European Medicines Agency. Pre-authorization Evaluation of Medicines for Human Use. EMEA/CHMP/PEG/194810/2005, 2006, http://www.emea.europa.eu

Expert Meeting on Dosage Forms of Medicines for Children, WHO Headquarters, Geneva, Switzerland. 2008. http://www.who.int/medicines/areas/quality_safety/quality_assurance/regu latory_standards /en/index.html

Fonner DE, Banker GS and Swarbrick J, Micromeretics of Granular Pharmaceutical Solids I. J Pharm Sci, 1966; 55 (2): 181 - 186

Ghebre - Sellassie. I. 1989. Pellets- A General Overview, in Ghebre - Sellassie I, Pharmaceutical Pelletization Technology, Marcel Dekker Inc, New York. pp. 187.

Halsted CH. Dietary supplements and The American Journal of Clinical Nutrition. Am J Clin Nutr, 2000; 71: 399-400

Heaney RP, Dowell MS, Bierman J., Hale CA and Bendich A. Absorbability and Cost Effectiveness in Calcium Supplementation. J. Am. Coll. Nutr., 2001; 20(3): 239-246.
Heller H.J, Stewart A, Haynes S.D, and Charles Y. C., Pharmacokinetics of Calcium Absorption from Two Commercial Calcium Supplements, J. Clin. Pharmacol. 1999; 39: 1151-1154

Kristensen H.G. WHO guideline development of pediatric medicines: Points to consider in pharmaceutical development, Int J Pharm, 2012; 435 (2): 134-135

Nicar MJ, Pak CY. Calcium bioavailability from calcium carbonate and calcium citrate. J Clin Endocrin \& Metab, 1958; 61: 391393

Podczeck F, Newton M. Influence of the standing time of the extrudate and speed of rotation of the spheroniser plate on the properties of pellets produced by extrusion and spheronization. Adv Powder Tech, 2014; 2 (2): 659-665

Poddar SS, Nandgude T, Muley S. Extrusion-spheronization a promising pelletization technique: In - depth review. Asian J Pharm, 2016; 11 (6): 684-699

Sakhaee K, Bhuket T, Adams Huet B, Rao DS. Meta-analysis of calcium bioavailability: A comparison of calcium citrate with calcium carbonate. Am J Ther, 1999; (6): 313 - 321.

Slavkova M, Jörg Breitkreutz M. Orodispersible drug formulations for children and elderly. Eur J Pharm Sci, 2015; 75: 2-9.

Swarbrick J. and Boylan J.C. 1998. Extrusion and Extruders, Encyclopedia of Pharmaceutical Technology, Volume 5, Marcel Dekker Inc, New York. pg $405-407$.

Vervaet C., Baert L. and Remon J.P. Extrusion Spheronization, A literature review. Int. J of Pharm, 1995; $116: 131$ - 142

Tatavarti A, Kesisoglou F An Extrusion Spheronization Approach to Enable a High Drug Load Formulation of a Poorly Soluble Drug with a Low Melting Surfactant. J Pharm Sci, 2015; 104 (11): 3752 3759 .

Wan L.C.S, Heng P.W.S and Liew C.V, Spheronization conditions on spheroid shape and size. Int. J. Pharm., 1993; 96: 59 - 65

Wildman REC. 2001. Nutraceuticals: A Brief Review of Historical and Teleological Aspects, in Handbook of Nutraceuticals and Functional Foods, CRC Press, Boca Raton. 1-11.

\section{How to cite this article:}

Desai N, Jain S, Singh P, SAmin P. Novel orodispersible compositions of nutraceuticals prepared by the technology of extrusion - spheronization. J App Pharm Sci, 2017; 7 (04): 031037. 